\title{
THE EXPERIENCE OF RE-READING
}

\section{Margaret Hunsberger}

The University of Calgary

What is it like to re-read? Having had one conversation with the text, why should we seek to return for another? On the other hand, why not? When a human voice speaks to us and we appreciate the conversation, value the friendship, we don't want to limit ourselves to one conversation only. But we don't want to have the same conversation over endlessly either. A friend will make different comments in the next conversation, whereas a text...? When we return to a text, does it give the same responses each time, or do they change? What is the nature of this ongoing conversation? Why do we sometimes choose to read a text more than once?

\section{Continuing Influence}

Sometimes it isn't until the end of a book that we realize that there is another dimension to the book that we haven't really picked up until then. This recognition of another dimension seems to happen particularly in novels which can be read just as story or can be read as allegory. Huckleberry Finn is a rollicking tale of a boy having adventures on the Mississippi in another century, but it is also a passage toward maturity on the river of life. If I am near the end before the second possibility occurs to me, a re-reading can be a most illuminating way of exploring the possibility. I now hold a different and more thoughtful conversation with the text.

Re-reading can be a way of moving ourselves forward, of deepening our understanding. So if as teachers we use a particular text repeatedly, each year we read it again and again, whether we want to or not. And each time we may see new things in it as we talk it over with our students. One teacher recounted how he had used One Flew Over the Cuckoo's Nest in his course for many years before it occurred to him that the book is "loaded" with Christian religious symbolism, "just shot all the way through."

Everyone in One Flew Over the Cuckoo's Nest is right out of the gospels. Realizing that gave me fresh insight into the relevance of the Christian story to twentieth century living. I saw that the events of the gospels are lived out at all times and in all places, or at least can be. The potential is there. And this message in the book is so subtle. It's just there for those who want to see it.

Not many books, of course, will have this large an impact on our lives and understanding. But it's quite common for people to mention a book that substantially altered their thinking, and even their living. 
Sometimes the impact comes on first reading, but often it builds through repeated readings. The insight may seem sudden, but it has been in preparation all along.

When shared communication occurs between text and reader, the re-reading is like another conversation with a friend, pursuing a wish to become better acquainted with the writer's thought. Rereading, then, is not a repeated conversation, but a new one. If in reading Watership Down I share with Hazel the responsibility he carries for the safety of the community, then I have changed. And so in re-reading a text I am a slightly different person than I was in the first reading. This is so even if the second reading occurs directly after the first, since the first reading has already altered me. If the two readings are more widely separated in time, my intervening experiences will have made even more difference in me. Thus each reading is somewhat different because the text is read by a person who brings new meanings to it, and therefore sees different meaning in it. Heap (1977), in considering this constant change, wonders how we achieve object constancy of texts. In a sense, we don't. Rather the text is different with cach reading because we are different.

Not only the reader, but also the text must be willing to allow for this reconsideration. The second reading "often produces a different impression from the first." The change may be in the reader's circumstances, but "the text must be such as to allow this variation. On a second reading familiar occurrences now tend to appear in a new light and seem to be at times corrected, at times enriched" (Iser, 1974, p. 280).

During a first reading of a text, the reader's interpretation is influenced by that part of the manuscript which has gone before. But in a re-reading the interpretation is influenced by both past and future text since the reader already knows what is yet to come. If I re-read A Tale of Two Cities, my interpretation of the first meeting of Sidney Carton and Charles Darnay in an English courtroom and of Carton's insolence and apparent contempt is colored by my knowledge that Carton will later voluntarily die that Darnay may live. My interpretation of Carton's character in the earlier episode is much more sympathetic since it is influenced by the knowledge of both Carton's selflessness and his self-contempt. Re-reading gives the reader a holistic view and a control of the text which is not possible in a first reading during which the reader trustingly and somewhat blindly follows the author's lead.

And this knowing what is ahead seems to enrich rather than "spoil" the story. You know that in Pride and Prejudice Elizabeth is going to marry Darcy. You know that, and yet you can re-read and still be upset by his arrogance. The re-reading does not only permit another involvement in the story; it adds dimensions. "If a novel is good, we 
do not miss the suspense of not knowing what is to happen next," says Lever. "On the contrary, the tension created by our foreknowledge and the inevitability of conclusion makes for far more absorbing reading than simple curiosity" (1961, p. 50). The reader's desire for a more complete grasp of the text may be why readers sometimes skip ahead and read the last few pages of a narrative early on. The attempt may be to get the benefits of re-reading during an actual first reading. It must partially fail since the intervening sections of the story do matter, but it also partially succeeds since, like re-reading, it allows the reader to use later information to interpret earlier text.

Sometimes the re-reading is just a pleasure. A grade one student will tell you that it's fun to re-read a book because, "It's easy. You know all the words." You first learn how to read the book and after that it's easy. For beginners who are still struggling to decode print this is an important factor. After learning to recognize the words and, thus, doing the work, they are free to enjoy the story.

Gina, a bright-eyed little girl in grade one, made an illuminating comment on why she would rather read a story herself than have it read to her by an adult. "Adults go too fast. You don't get a chance to listen. I say 'Read me a story,' and they say, 'I already did.' " Gina's statement shows one reason why children want the same story repeated so often. They need "a chance to listen" to all the aspects and implications that interest them in the story.

The primary conversation in reading is between reader and text. But there is also the possibility for two readers to share a text. Although reading itself is a very individual activity, readers like to share their reactions to a text with each other. Having a friend read the same book I have read and then getting together to discuss it is fun. During the discussion the text is consulted as one person wants to prove a point or as it becomes apparent that we have made differing interpretations of a section of the text. I cannot be sure that I have grasped the complete meaning of the text, or even that I have made an interpretation consistent with the author's intent. In conversation this uncertainty is the basis for most of the references to re-reading ("I think it means ... but I have to read and re-read this"). The more complex the reader finds the text to be, the more that is so. For a reader it is interesting if someone shares our view, but it can be equally productive if someone has read the same book but has not had the same reaction. The diversity leads to re-reading and re-assessment because we can get bound by our own areas of interest. While the diverse interpretations can be stimulating, there is implicit in the interpretive activity the impetus toward community. If two readers disagree and walk away, there is no need for reassessment. But that abandonment is accompanied by discontent. We do 
seek to share a view. Merleau-Ponty (1964) uses the example that when two friends are viewing a landscape and one sees something the other does not, the first person does not want the friend to see an analogous world but to see the same thing. We have probably all had the experience of hearing an impatient tone enter our friend's voice when we have been unable to see what was being pointed out, or of feeling impatient when a friend failed to comprehend our observation. Similarly, in discussing a text I would like my friend to take my point, to "see what I mean." Not surprisingly, that frequently does not happen as my friend responds to the text and to my interpretation of it from a very different perspective, that of personal inner time. If we then re-read the text in light of each other's comments, a second discussion may possibly find us seeing a more shared landscape; it will certainly find us seeing a different one than we first saw.

This opportunity for discussion and sharing is as necessary between pupil and teacher as between friends, although the nature of the relationship, and hence the discussion, differs somewhat. In curriculum theory of reading, the term "instructional level" is used to designate those texts that a child can read with the teacher's help. That is, they are neither so difficult as to be beyond the child's understanding, nor so easy that the child can comprehend them independently. But understanding grows if there is opportunity for discussion with the teacher, if the child can ask about puzzling ideas, if the teacher can ask questions that intrigue and challenge, if they can genuinely share ideas. If the stance of lovers is face to face seeing nothing but each other, and the stance of friends is shoulder to shoulder looking out at a shared world (Lewis, 1960), perhaps the stance of teachers and pupils is the teacher looking over the child's shoulder sharing involvement in the child's activity and learning. When a teacher re-reads in preparation for teaching, the attitude is one of seeking for ways to share insight. And out of that search, new insights are born. The pupil, on the other hand, re-reads as part of the struggle to interpret, to understand. But again, new insights are born. And who of us as teachers have not had our understanding of familiar text deepened by the thoughtful comments of our young students? The sharing truly works both ways.

\section{Oral Reading as Re-Reading}

All of the foregoing comments have assumed a silent reading of the text, a situation in which the reader is alone with the text, either by actually being in a room alone or, if others are present, by not being disturbed. The interaction is between reader and text, and through text to the absent author. Silent reading is a solitary activity which does not require another person to be present, and actually works best if no one else is there. 
Oral reading is a very different matter. It requires an audience. And it is normally a re-reading which has been prepared by the reader. That is, a person who anticipates reading aloud takes the text and reads it silently, often several times, deciding first what interpretation is to be conveyed and, therefore, what voice inflections, pitch, and stress will best convey the meaning. The reader prepares the presentation as an actor rehearses a role, and for exactly the same reason: each is giving a performance. In an oral reading the interaction is no longer between reader and text; rather there is a bonding together of reader and text so that they in combination can interact with the audience. The whole reason for the activity shifts. This is demonstrated when oral readers, unless they are on the radio, try to look at the text as little as possible and at the audience as much as possible-a procedure that is obvious nonsense in silent reading. The newscaster on the air, the minister in church, or the parent with young child-none of them is reading aloud to find out for themselves what the text says, rather they are attempting to communicate to their listeners what they already know about it. It is possible to give an expressive oral reading with minimal attention to the meaning being conveyed; this happens because the reader is attending to the performance and the reaction of the audience rather than to the text. In these circumstances it is unlikely that the reader will learn very much new about the text, except possibly that a certain sequence of words is difficult to pronounce without stumbling.

The most expressive oral readings are probably those in which the reader feels confident enough in the situation to be free to attend to the text; that requires, among other factors, preparation of the reading. Lack of preparation, combined with attention to the social context rather than the text, is likely to result in a less expressive reading. During a discussion of this subject with a friend, he recalled an experience when, as a college student, he was asked to read aloud in class. When he finished, the teacher said, "I don't believe you know what you have just read. Tell me what it was about." The teacher had rightly detected that my friend's attention was not on the text itself. By remembering his own voice, as it were, saying the words and by rapidly skimming the text in front of him, my friend was able to give a summary of the content. While he regarded the experience as a narrow escape from embarrassment and the teacher was deceived into thinking that he had comprehended the first time, my friend's failure to think about the text during the oral reading was a much more common experience than either of them may have realized.

This may call into question the traditional classroom practice of asking young children to read aloud from an unfamiliar text and then to answer comprehension questions on it immediately afterwards. It explains, however, why the other members of the class 
often are better able to answer than the child who reads aloud; the others had time to think since they did not have to perform. The point here is not to say that children should never read aloud-expressive oral reading is a very useful skill-rather it is to question the intent and the circumstances under which the reading often takes place in the classroom. Oral reading, then, needs to be a rereading. It is a performance and should not be confused with a silent re-reading which is a very different experience.

The only way that a reader can read a text without making an interpretation is to read with no meaning in mind. As soon as the reader has a meaning in mind, not only has the possibility of interpretation been made available, but at least a tentative interpretation is already forming. The experience of listening to a chanted oral reading soon makes apparent how difficult it is to extract meaning and therefore how thoughtless it is. Such an oral rendition without meaning may have ceremonial value, but it has nothing to do with re-reading since the whole purpose of re-reading is to interpret and reinterpret.

\section{A Shared World}

What then is it like to re-read? The essence of re-reading appears to be found in interaction and sharing. The reader interacts with the text and through it with the author in the pursuit of further questions and answers and of a familiar and secure world in which to dwell. Sharing also occurs between readers who seek, through continued dialogue with each other and the text, a mutual interpretation of the text so that they may establish a shared world. And so, although "Printed texts reach man in solitude, far from the ceremonies that gather the community" (Ricoeur, 1976, p. 42), the texts also bring with them into the solitude, not the ceremonies but some sense of the community. Thus, while one aspect of the re-reading activity is done alone, re-reading very fundamentally involves engagement with both author and other readers-two differing but vital kinds of interaction and sharing.

\section{References}

Gadamer, H.-G. (1975). Truth and method. New York: Seaburg Press.

Heap, J. (1977). Toward a phenomenology of reading. Journal of Phenomenological Psychology, 8, 103-114.

Iser, W. (1974). The implied reader. Baltimore: Johns Hopkins University Press.

Lever, K. (1961). The novel and the reader. London: Methuen \& Co.

Lewis, C. S. (1960). The four loves. Glasgow: Collins.

Merleau-Ponty, M. (1964). The primacy of perception. Evanston, IL: Northwestern University Press. 